\title{
Plasminogen Activator Inhibitor-1 (PAl-1) deficiency predisposes to depression and resistance to treatments
}

\author{
Hélène Party ${ }^{1}$, Cléo Dujarrier ${ }^{1 \dagger}$, Marie Hébert ${ }^{2 \dagger}$, Sophie Lenoir ${ }^{1}$, Sara Martinez de Lizarrondo ${ }^{1}$, Raphaël Delépée ${ }^{3}$, \\ Claudine Fauchon ${ }^{4}$, Marie-Christine Bouton ${ }^{5}$, Pauline Obiang ${ }^{1}$, Olivier Godefroy ${ }^{6}$, Etienne Save ${ }^{7}$, \\ Laurent Lecardeur ${ }^{8,9}$, Joëlle Chabry ${ }^{10}$, Denis Vivien ${ }^{1,11^{*+}}$ and Véronique Agin ${ }^{1 *+}$ (D)
}

\begin{abstract}
Major depressive disorder (MDD) is one of the most frequent psychiatric illnesses, leading to reduced quality of life, ability to work and sociability, thus ranking among the major causes of disability and morbidity worldwide. To date, genetic and environmental determinants of MDD remain mostly unknown. Here, we investigated whether and how the Plasminogen Activator Inhibitor-1 (PAI-1) may contribute to MDD. We first examined the phenotype of PAI-1 knockout (PAl-1-/-) and wild-type (PAI-1+/+) male mice with a range of behavioral tests assessing depressive-like behaviors $(n=276)$. We next investigated the mechanisms relating PAI-1 to MDD using molecular, biochemical and pharmacological analyzes. We demonstrate here that PAl-1 plays a key role in depression by a mechanism independent of the tissue-type Plasminogen Activator (tPA) - Brain-Derived Neurotrophic Factor (BDNF) axis, but associated with impaired metabolisms of serotonin and dopamine. Our data also reveal that PAI-1 interferes with therapeutic responses to selective serotonin reuptake inhibitors (escitalopram, fluoxetine). We thus highlight a new genetic preclinical model of depression, with the lack of PAl-1 as a factor of predisposition to MDD. Altogether, these original data reveal that PAI-1 should be now considered as a key player of MDD and as a potential target for the development of new drugs to cure depressive patients resistant to current treatments.
\end{abstract}

Keywords: Major depressive disorder, Plasminogen activator Inhibitor-1, Serotonin, Dopamine, Escitalopram, Fluoxetine, Genetic model of depression, Resistance to selective serotonin reuptake inhibitors

\section{Introduction}

Major depressive disorder (MDD) is one of the most frequent psychiatric illnesses, leading to reduced quality of life, ability to work and sociability, thus ranking among the major causes of disability and morbidity worldwide $[19,40,50]$. To date, genetic and environmental determinants of MDD remain mostly unknown $[8,15,27,34$, 41]. MDD is defined by major depressive episodes (MDE) which are characterized by five or more out of the nine following symptoms $[2,49]$ : depressed mood", markedly diminished interest or pleasure* (anhedonia),

\footnotetext{
*Correspondence: vivien@cyceron.fr; agin@cyceron.fr

${ }^{\dagger}$ Cléo Dujarrier and Marie Hébert contributed equally to this work.

${ }^{\dagger}$ Denis Vivien and Véronique Agin contributed equally to this work.

'UNICAEN, INSERM, INSERM UMR-S 1237, Physiopathology and Imaging of

Neurological Disorders, Normandie University, 14000 Caen, France

Full list of author information is available at the end of the article
}

change in weight or appetite, insomnia or hypersomnia, psychomotor retardation or agitation, fatigue or loss of energy, feelings of worthlessness or excessive or inappropriate guilt, impaired concentration or indecisiveness, thoughts of death or suicidal ideation or attempt (* one or two of these symptoms must be present). These symptoms must induce altered functioning, cause significant distress or impairment, and should not be attributed to a drug substance or medical condition. MDD is diagnosed only if MDE is not better explained by a psychotic disorder and if there is no history of mania or hypomania.

Current pharmacological treatments mainly consisting in selective serotonin reuptake inhibitors (SSRIs) are effective, however approximately $30-40 \%$ of patients are resistant to such treatments $[1,13,16,41,51,52]$. Moreover, even in responsive people, effects of antidepressants

(C) The Author(s). 2019 Open Access This article is distributed under the terms of the Creative Commons Attribution 4.0 International License (http://creativecommons.org/licenses/by/4.0/), which permits unrestricted use, distribution, and 
are often delayed and induce disabling side effects [23, 31]. Therefore, there is a need for a better understanding of the pathophysiology of MDD in order to propose innovative treatments.

An abundant literature suggests that the Plasminogen Activator Inhibitor-1 (PAI-1) could be involved in MDD. For example, PAI-1 is found in brain structures related to mood regulation (e.g. amygdala, hippocampus, prefrontal cortex) and in blood circulation [6, 22, 30, 36, 45]. Several clinical studies have reported increased levels of plasmatic PAI-1 in depressed patients [14, 22, 24, 32]. Convergent with these findings, Tsai et al. [48] demonstrated that the genetic variants of SERPINE1 gene (coding PAI-1) in humans may increase MDD susceptibility and decrease the acute therapeutic response to SSRIs. At the preclinical scale, increased concentrations of cerebral PAI-1 have been found in rats exposed to a chronic unpredicted mild stress (CUMS) procedure [45]. All together, these studies suggest that PAI-1 could be a biomarker of depression, although its direct and precise implication in MDD pathogenesis has not been demonstrated.

The possible implication of PAI-1 in the pathogenesis of depression also emerged from the neurotrophic hypothesis of depression [3, 18, 37]. Among neurotrophins, Brain-Derived Neurotrophic Factor (BDNF) has been repeatedly shown to be implicated in MDD as well as in the mechanisms of action of antidepressants $[4,9,37$, $47,54]$. BDNF arises from a precursor, proBDNF, which is proteolytically cleaved by the tissue-type Plasminogen Activator (tPA) - plasminogen system to produce the mature protein, mBDNF $[26,35]$. Whereas mBDNF facilitates long-term potentiation and prevents apoptosis, the proBDNF is involved in hippocampal long-term depression and cell death mechanisms [29, 35, 46, 53]. Because PAI-1 is one of primary inhibitors of tPA, it was proposed that PAI-1 may be involved in the pathogenesis of MDD through inhibition of the proBDNF cleavage via its interaction with the tPA-plasminogen system.

Here, we investigated whether and how PAI-1 may contribute to MDD. PAI-1 knockout mice and tPA knockout mice were submitted to a range of behavioral tests that exhaustively assess depressive-like symptoms. Furthermore, we investigated the mechanisms relating PAI-1 to MDD using molecular, biochemical and pharmacological analyzes.

\section{Materials and methods}

\section{Animals}

Ten weeks old C57BL/129 PAI-1 knockout (PAI-1-/-) and C57BL/129 tPA knockout (tPA-/-) male mice and their corresponding wild-type littermates (PAI-1+/+; tPA $+/+$ ) were used in this study $[6,7]$. The strain, number and age of mice used in each experiment are summarized in the Additional file 6: Table S1. All the experiments were approved by the French ministry of education and research (agreement numbers APAFIS\#5115 and APAFIS\#4359). The principal investigator (VA, personal license number 14-73) was accredited by the "Direction Départementale des Services Vétérinaires". The animal investigations were performed under the current European directive (2010/63/EU) as incorporated in national legislation (Decree 87/848) and in authorized laboratories (GIP Cyceron; approval $\mathrm{n}^{\circ}$ E14118001). Further details are described in the Additional file 1: Additional Materials and Methods.

\section{Assessment of depressive-like behaviors}

We first set-up a depression screening system in mouse ( $n=276$; see Additional file 7: Table S2) to characterize the potential depressive-like phenotype of PAI-1 and tPA mice. To this aim, a range of behavioral tests were used for assaying each depression symptom: splash test, sucrose preference test, body weight, actimetry, rotarod, coat state, T-maze and forced swimming test. They are described in the Additional file 1: Additional Materials and Methods. Our methodological preclinical model thus consisted of exhaustively scoring primary (apathetic and anhedonic behaviors) and secondary (hypo- or hyperactivity, loss of motivation/effort, body weight, deficits of self-centered behaviors, cognitive deficits) depressive criteria (see Additional file 7: Table S2) by means of behavioral tests. One point was attributed when a significant difference was yielded between knockout and wild-type mice; the score was equal to 0 when there was no significant difference between groups. Thereafter, all the scores were added together forming a composite score. At the end, the depression-like phenotype was retained if and only if the composite score was at least equal to 4 points, including necessarily at least one of the two primary criteria.

\section{Perfusion and sampling}

Animals were deeply anesthetized with isoflurane 5\%, and thereafter maintained with $2.5 \%$ isoflurane in a $70 \% /$ $30 \%$ mixture of $\mathrm{NO}_{2} / \mathrm{O}_{2}$. A transcardial perfusion was performed with ice cold $0.9 \% \mathrm{NaCl}$ heparinized. Further details are described in the Additional file 1: Additional Materials and Methods.

\section{Protein extraction}

Tissues were dissociated in ice-cold TNT buffer $(50 \mathrm{mM}$ Tris- $\mathrm{HCl} \mathrm{pH} 7.4 ; 150 \mathrm{mM} \mathrm{NaCl} ; 0.5 \%$ Triton X-100; Sigma-Aldrich, Saint-Quentin Fallavier, France), centrifuged for $20 \mathrm{~min}\left(12,000 \mathrm{~g}\right.$ at $\left.4{ }^{\circ} \mathrm{C}\right)$, then protein concentration was quantified using the $\mathrm{BCA}$ method (Pierce, Rockford, IL, USA). 


\section{Fibrin-agar zymography assay}

Proteins $(20 \mu \mathrm{g})$ were electrophoresed in a $8 \%$ polyacrylamide gel under non reducing conditions. SDS was then exchanged with $2.5 \%$ Triton X-100 (Sigma-Aldrich). After washing off excess Triton X-100 with distilled water, the gel was carefully overlaid on a $1 \%$ agarose indicator support containing bovine fibrinogen, plasminogen and thrombin. Zymograms were then allowed to develop at $37^{\circ} \mathrm{C}$ during several days and photographed at regular intervals using dark-ground illumination. Data were normalized to the mean value obtained for wildtype mice. Results shown are representative pictures of the zymograms and the corresponding quantifications made by calculating the area under the curve for each lysis band by using the ImageJ software (NIH).

\section{Immunoblotting}

Proteins $(20 \mu \mathrm{g})$ were resolved on 4-20\% SDS-PAGE gel (Bio-rad, Marnes-la-Coquette, France) under denaturing conditions and transferred onto a polyvinylidene difluoride membrane. Membranes were blocked with Tris-buffered saline (TBS: $10 \mathrm{mM}$ Tris and $200 \mathrm{mM} \mathrm{NaCl}, \mathrm{pH} 7.4$ ) containing $0.05 \%$ Tween-20 and $1 \%$ BSA. Blots were incubated overnight at $4{ }^{\circ} \mathrm{C}$ in blocking buffer with the primary antibody: rabbit anti-mBDNF (1/5000; ab108319; Abcam, Paris, France), rabbit anti-proBDNF (1/100; ab72440; Abcam) or rabbit anti-actin (1/1000; A2066; Sigma-Aldrich). Membranes were then incubated with peroxidaseconjugated anti-rabbit secondary antibodies (1/50000; Sigma-Aldrich). Proteins were visualized with an enhanced chemiluminescence western blot detection reagent (ECL Prime Western Blotting System; GE Healthcare; RPN2232) using ImageQuant LAS 4000 Camera Camera (GE Healthcare, Chicago, IL, USA).

\section{Ultra-high-pressure liquid chromatography coupled with tandem-mass spectrometry (UHPLC-MS/MS)}

We developed and validated a novel UHPLC-MS/MS method for quantification of dopamine (DA), noradrenaline (NA) and serotonin (5-HT) in mice brain structures. Briefly, the method consisted in crushing in formic acid aqueous solution in acetonitrile containing acetic acid. The samples were then centrifuged and injected in the UHPLC-MS/MS system and quantification was obtained by a $1 / \mathrm{X} 2$ weighted calibration curves using the internal standard method. Lower limits of quantification in the injected solutions were $0.1 \mathrm{ng} / \mathrm{mL}$ for DA and $5-\mathrm{HT}$, and $0.5 \mathrm{ng} / \mathrm{mL}$ for NA. For further detail, see Additional file 1: Additional Materials and Methods and Additional file 8: Table S3.

\section{Drug administration}

Escitalopram (ESC) and fluoxetine (FLX) were purchased from Carbosynth (Compton-Bershire, United Kingdom). Both drugs were dissolved in saline $(\mathrm{NaCl} 0.9 \%)$ and were administrated intraperitoneally (i.p.) at a concentration of $15 \mathrm{mg} / \mathrm{kg}(1 \mathrm{mg} / \mathrm{ml})$ or $30 \mathrm{mg} / \mathrm{kg}(2 \mathrm{mg} / \mathrm{ml})$ body weight. The drug dose was chosen based on previous preclinical studies [5, 11, 12, 17, 43]. Control groups received an equivalent volume of saline (vehicle: $\mathrm{VEH})$. Mice were i.p. injected daily with ESC or FLX, or VEH, for 35 consecutive days. The behavioral tests were conducted from day 22 to day 35 of antidepressant treatment.

\section{Statistical analysis}

Statistical analyses were performed using STATISTICA $\mathrm{PRO}^{\circ}$ v13.0 software (StatSoft, Inc.). The distribution of samples was studied with Shapiro-Wilk's tests. When data were normally distributed, Student's $t$-tests were used. When analysis of the data sets via parametric approaches turned out to be inappropriate due to violation of residual normality, non-parametric approaches where used (Mann-Whitney's $U$-tests for independent samples or Wilcoxon's signed-rank tests for matched samples). An alpha level of $p<0.05$ was used for determination of significance in all statistical tests; all tests are two tailed.

\section{Results}

PAI-1 deficiency results in a depressive-like phenotype in mice

After setting up a depression screening system in mouse (see Additional file 7: Table S2), we have characterized the behavioral phenotype of PAI-1-/- and PAI- $1+/+$ mice. In the splash test, PAI-1-/- mice exhibited decreased frequency of grooming behavior when compared to PAI-1+/ + control mice (Fig. 1a; $U=506 ; P=0.042$ ), thus pointing to apathetic behavior in PAI-1-/- mice (Table 1; score = 1). A significant alteration of the coat state of PAI-1-/mice was found (Fig. 1b; PAI-1-/-: 2.58; PAI-1+/+: 1.27; $\mathrm{U}=357.5, P=0.00007)$ indicating a deficit of self-centered behaviors (Table 1; score $=1$ ). PAI-1-deficient mice also decreased preference for sucrose containing water compared to PAI- $1+/+$ mice (Fig. $1 \mathrm{c} ; \mathrm{t}=4.08, P=0.00011$ ), demonstrating an anhedonic behavior in PAI-1-/- mice (Table 1; score $=1$ ). In addition, there was a significant difference in the body weight between the two genotypes (Fig. $1 \mathrm{~d}$; $\mathrm{t}=2.08, P=0.047 ; 24.12 \mathrm{~g} \pm 1.60$ for PAI-/- mice versus $25.54 \mathrm{~g} \pm 2.11$ for PAI- $1+/+$ mice) (Table 1 ; score $=$ 1). In terms of actimetry, both groups of mice showed a similar locomotor activity (Fig. 1e; PAI-1-/-: number of movements $=746 \pm 211$; PAI- $1+/+$ : number of movements $=694 \pm 191 ; \mathrm{t}=-1.13, P=0.261)$. In contrast, PAI1-/- mice exhibited altered rotarod performance; indeed, latencies to fall were $57.35 \mathrm{~s}$ and $84.51 \mathrm{~s}$ for knockout and wild-type mice, respectively (Fig. 1 f; $\mathrm{t}=4.83, P=0.00001$ ). These results suggest impairment in motivation/effort in PAI-1 knockout mice (Table 1; score =1). Finally, spatial cognitive abilities were examined by using a place recognition task in a T-maze which required the use of room 


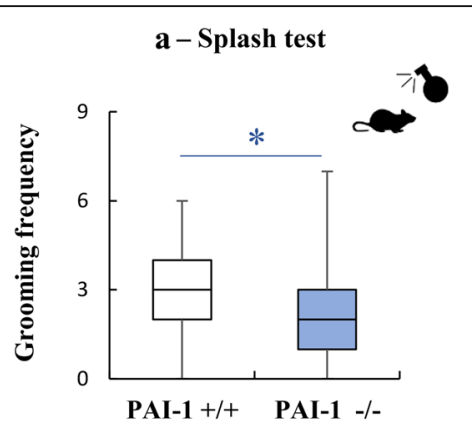

c-Sucrose preference test

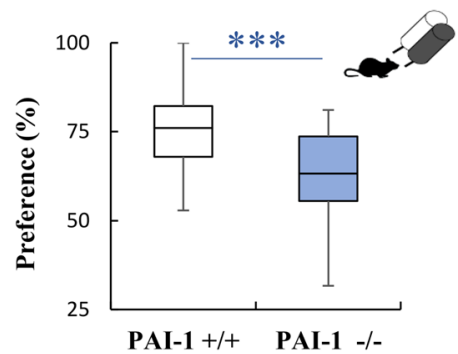

e- Actimetry
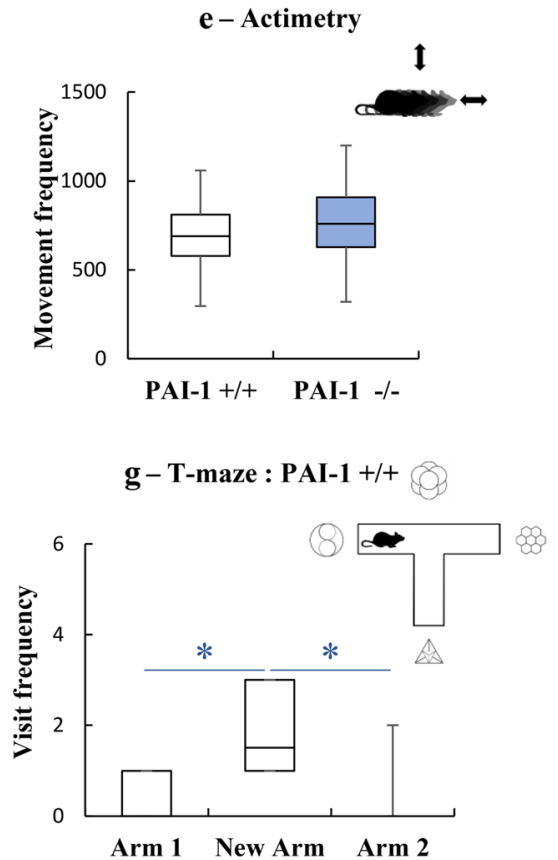

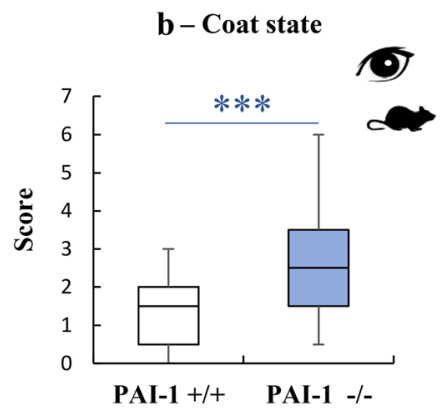

d- Body weight

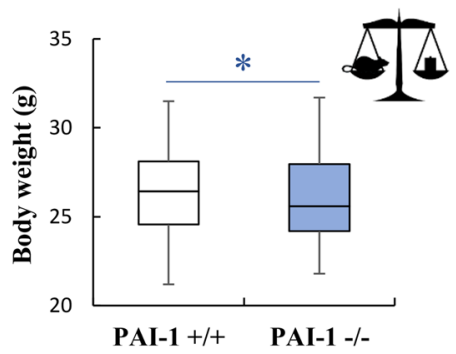

f- Rotarod

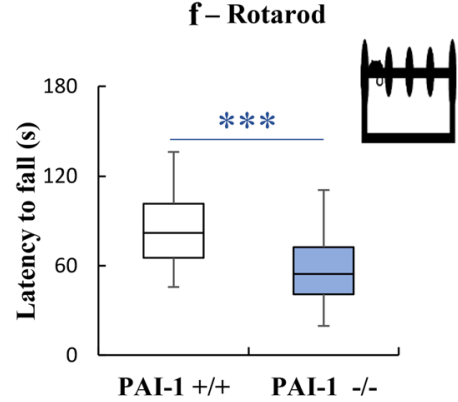

h-T-maze : PAI-1 -/-

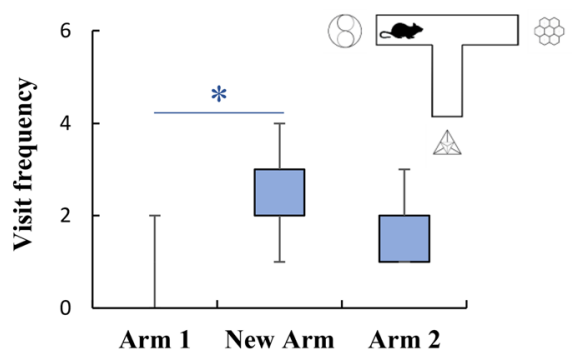

Fig. 1 PAl-1 deficiency induces a depressive-like phenotype. Evaluation of the behavioral phenotype of PAl-1 knockout mice (PAl-1-/-) and of their wild-type littermates (PAl-1+/+). a Splash test: $\mathrm{n}_{\mathrm{PAl}-1+/+}=34 ; \mathrm{n}_{\mathrm{PAl}-1-/-}=41$. $\mathbf{b}$ Coat state: $\mathrm{n}_{\mathrm{PAl}-1+/+}=35 ; \mathrm{n}_{\mathrm{PAl}-1-/-}=42$. $\mathbf{c}$ Sucrose preference test: $\mathrm{n}_{\mathrm{PAl}-1+/+}=35 ; \mathrm{n}_{\mathrm{PAl}-1-/-}=39$. $\mathbf{d}$ Body weight: $\mathrm{n}_{\mathrm{PAl}-1+/+}=15 ; \mathrm{n}_{\mathrm{PAl}-1-/-}=15$. e Actimetry: $\mathrm{n}_{\mathrm{PAl}-1+/+}=35 ; \mathrm{n}_{\mathrm{PAl}-1-/-}=42 . \mathbf{f}$ Rotarod: $\mathrm{n}_{\mathrm{PAl}-1+/+}=33 ;$ $\mathrm{n}_{\mathrm{PAl}-1-/-}=40 . \mathbf{g}$, h T-maze: $\mathrm{n}_{\mathrm{PAl}-1+/+}=12 ; \mathrm{n}_{\mathrm{PAl}-1-/-}=9$. Mann-Whitney U-tests $(\mathbf{a}, \mathbf{b})$, Student $\mathrm{t}$ tests $(\mathbf{c}-\mathbf{f})$, Wilcoxon signed-rank tests $(\mathbf{g}, \mathbf{h}):{ }^{*} P<0.05$, ${ }^{* *} P<0.01$, ${ }^{* *} P<0.001$. Boxplots show distributions with black horizontal lines indicating the median, box margins denoting the lower and upper quartiles. Whiskers show the minimum and maximum values

cues. During the test phase, PAI- $1+/+$ mice discriminated correctly the newly opened arm from the familiar ones since they visited significantly more often the new arm than arms 1 and 2 (Fig. 1g; Arm 1 vs New arm: $Z=2.37$,
$P=0.018$; Arm 2 vs New arm: $Z=2.10 P=0.036$ ), therefore indicating good spatial performance in control mice. PAI-1-/- mice entered more often in the new arm relative to familiar arm 1 (Fig. $1 \mathrm{~h}$; Arm 1 vs New arm: $\mathrm{Z}=$ 
Table 1 Depressive-like phenotype in mice. Relative score of PAl-1 knockout mice and tPA knockout mice

\begin{tabular}{|c|c|c|c|}
\hline \multicolumn{2}{|l|}{ Depressive-like behaviors in mice } & \multirow{2}{*}{$\frac{\text { PAl-1-/- }}{1}$} & \multirow{2}{*}{$\frac{\mathrm{tPA}-/-}{0}$} \\
\hline Apathetic behavior & Splash test & & \\
\hline Anhedonic behavior & Sucrose preference test & 1 & 0 \\
\hline Body weight & Balance & 1 & 1 \\
\hline Hypoactivity or hyperactivity & Actimetry & 0 & 0 \\
\hline Loss of motivation/effort & Rotarod & 1 & 0 \\
\hline Deficits of self-centered behaviors & Coat state & 1 & 1 \\
\hline Cognitive deficits & T-maze & 1 & 1 \\
\hline Composite Score & & 6 & 3 \\
\hline
\end{tabular}

PAl-1-/- PAI-1 knockout mice, tPA-/- tPA knockout mice

2.37, $\mathrm{P}=0.018$ ). However, the number of visits of the familiar arm 2 was not different from the newly open arm (Fig. 1h; $\mathrm{Z}=1.68, P=0.093$ ). These observations reveal that the deficiency of PAI-1 alters the ability of mice to orientate properly (Table 1 ; score $=1$ ). Overall, considering all behavioral procedures described above, PAI-1-/mice obtained a composite score of 6 points, which is equivalent to six depressive-related symptoms of the screening system, including apathetic and anhedonic behaviors, two hallmarks of MDD in humans (Table 1, column 2; see Additional file 7: Table S2). Conversely, $\mathrm{PAI}+/+$ mice showed any symptom. Altogether, these results demonstrate a depressive-like phenotype in PAI-1 -/- mice. Interestingly, this deficit observed in PAI-1 -/mice cannot be attributed to any brain weight or volume disparity (see Additional file 2: Figure S1; see Additional file 1: Additional Materials and Methods).

\section{The depressive-like phenotype of PAI-1-/- mice is independent of the tPA-BDNF axis}

To determine whether the involvement of PAI-1 in depression was associated, or not, with its interaction with tPA, we also examined the behavioral phenotype of tPA -/- mice and that of their wild-type littermates with our depression screening system (see Additional file 7: Table S2; see Additional file 3: Figure S2). At the end of the behavioral tests, tPA knockout mice reached a composite score of 3 (Table 1, column 3). Importantly, they did not exhibit apathetic or anhedonic behavior. Thus, deficiency in tPA does not influence the depressive-like phenotype of mice compared to their wild-type littermates. This first set of behavioral tests suggests that the depressive-like phenotype observed in PAI-1-/- mice is tPA-independent.

The next step of our study examined cerebral tPA and BDNF levels in several brain structures related to depression (prefrontal cortex, hippocampus, hypothalamus) in PAI-1-/- and PAI-1+/+ mice. tPA activity was similar in both groups of mice whatever the brain areas (Fig. 2a: $\mathrm{t}=-0.12, P=0.907$; Fig. 2c: $\mathrm{t}=-0.52, P=0.618$; Fig. 2e: $\mathrm{t}=-1.51, P=0.170)$. These data argue for a role of
PAI-1 in depression-like behaviors by a mechanism independent of its role of tPA inhibitor. To ascertain this claim, we measured the levels of mBDNF in the same areas of PAI-1-/- and PAI- $1+/+$ mice. Our results revealed that the neurotrophin levels did not differ between groups (Fig. 2b: $\mathrm{t}=-2.04, P=0.076$; Fig. 2d: $\mathrm{t}=-0.91, P=0.387$; Fig. 2f: $\mathrm{t}=1.65, P=0.138)$. These data thus confirm the role of PAI-1 in depression, by a mechanism independent of the tPA-plasminogenBDNF axis.

\section{PAl-1 deficiency is associated with reduced levels of parenchymal 5-HT and DA}

Given the monoaminergic hypothesis of MDD, we measured the levels of 5HT, NA and DA in brain structures (prefrontal cortex, hippocampus, hypothalamus, dorsal raphe) in PAI-1-/- and PAI-1+/+ mice. Our data demonstrate a significant decrease of 5-HT levels in prefrontal cortex of PAI-1 knockout mice when compared with those of PAI- $1+/+$ mice (Fig. 3a; $U=0, P=0.008$ ). In hippocampus and dorsal raphe, the levels of DA were also significantly reduced in PAI-1-/- mice when compared to control mice (Fig. 3b, d; Hippocampus: $\mathrm{U}=0$, $\mathrm{P}=0.008$; Raphe: $\mathrm{U}=0, \mathrm{P}=0.008$ ). The levels of NA were not affected by PAI-1 deficiency whatever the brain area (Fig. 3a: $\mathrm{U}=6, P=0.222$; Fig. 3b: $\mathrm{U}=8, P=0.421$; Fig. 3c: $U=10, P=0.690$; Fig. 3d: $U=4 ; P=0.095$ ). Altogether, these data reveal a strong relationship between the amounts of 5-HT and DA present in specific cerebral structures and the expression of PAI-1.

\section{PAI-1 is necessary to mediate the antidepressant effects of SSRIs}

Because SSRIs are the most frequently prescribed antidepressants [41], we tested the effects of treatment with escitalopram, or fluoxetine, in PAI-1-/- mice. For this pharmacological study, we replaced the cognitive task of our screening behavioral tests by the forced swimming test (FST) as it is the gold standard assay for screening of antidepressant drugs. We first applied an escitalopram chronic treatment (35 days) at $15 \mathrm{mg} / \mathrm{kg}$. The data 

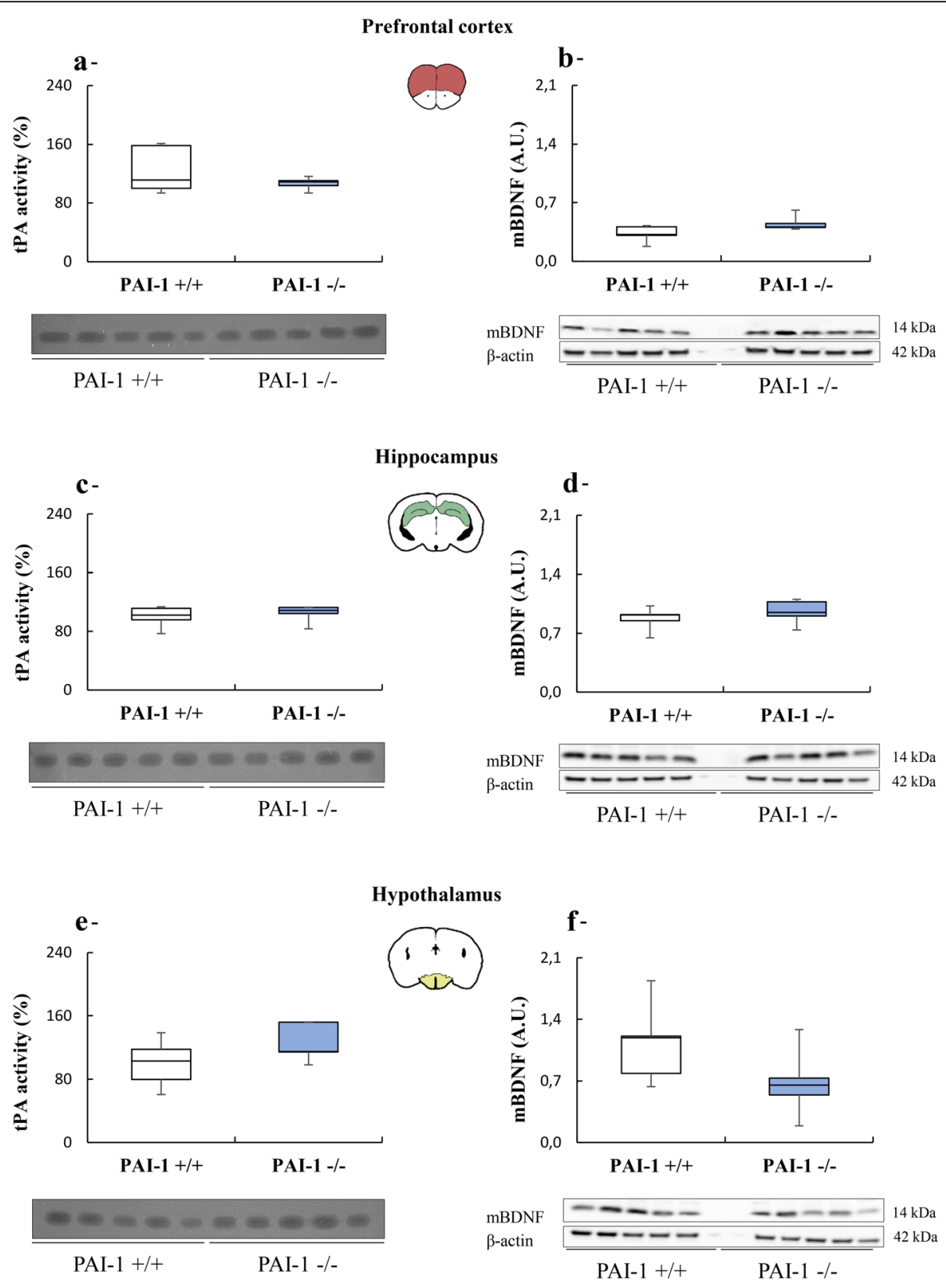

Fig. 2 Influence of PAl-1 deficiency on depressive-like phenotype is independent of tPA and mBDNF. Fibrin-agar zymography assays (tPA proteolytic activity) and immunoblots (mBDNF levels) in the prefrontal cortex (a, b), hippocampus (c, d), and hypothalamus (e, $\mathbf{f})$ of PAl-1 knockout mice (PAl-1-/-) and of their wild-type littermates (PAl-1+/+). $n=5$ for each structure / genotype. Student $t$ tests: $P>0.05$. Boxplots show distributions with black horizontal lines indicating the median, box margins denoting the lower and upper quartiles. Whiskers show the minimum and maximum values

showed that none of the depressive-like symptoms was counterbalanced by the escitalopram treatment in PAI-1 $-/-$ mice (Fig. 4a: $\mathrm{U}=114.5, P=0.207$; Fig. 4b: $\mathrm{t}=-0.99$, $P=0.328$; Fig. 4c: $\mathrm{U}=105, P=0.118$; Fig. $4 \mathrm{~d}: \mathrm{U}=100$, $P=0.083$; Fig. 4e: $\mathrm{t}=-1.43, P=0.161$; Fig. 4f: $\mathrm{t}=-1.36$, $P=0.186$ ). This was also true for the FST since the duration of immobility was similar for the two groups (Fig. 4g: $\mathrm{U}=112, P=0.274)$. We then examined the effect of a higher dose of the same antidepressant, i.e. $30 \mathrm{mg} / \mathrm{kg}$ i.p. This second experiment confirmed our previous observation that chronic treatment with escitalopram did not exert antidepressant-like effect in PAI-1-/- mice, whatever the dose administered or the assessed symptom (see Additional file 4: Figure S3a: $U=65, P=0.712$; see Additional file 4: Figure S3b: $\mathrm{t}=1.11, P=0.281$; see Additional file 4: Figure S3c: $U=56, P=0.378$; see 


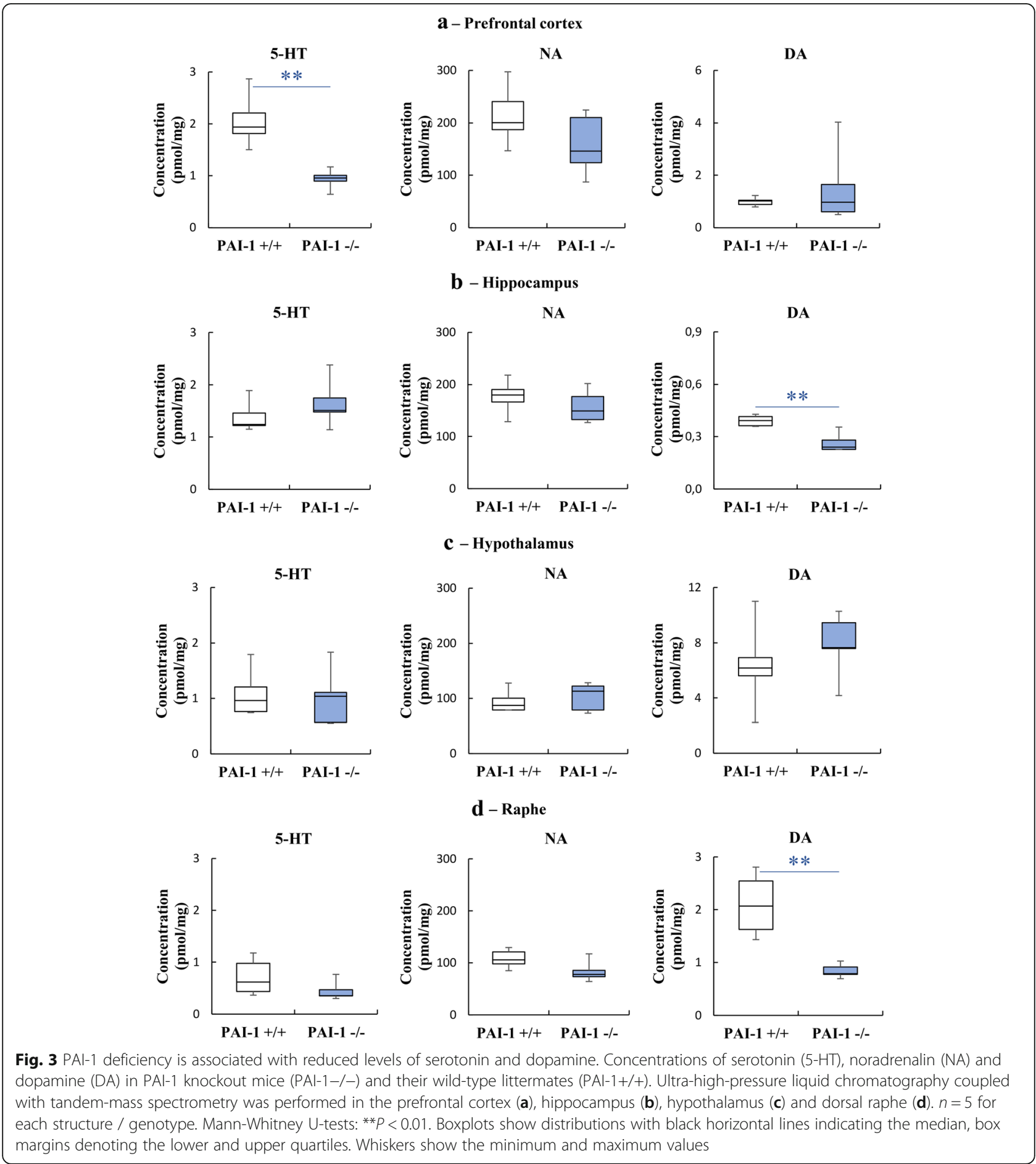

Additional file 4: Figure S3d: $\mathrm{t}=-0.86, P=0.397$; see Additional file 4: Figure S3e: $U=58, P=0.443$; see Additional file 4: Figure S3f: $t=-0.92, P=0.369$; see Additional file 4: Figure S3 $\mathrm{g}: \mathrm{t}=0.96, P=0.348$ ). To further understand whether this lack of efficacy was specific to escitalopram or generalized to other SSRIs, we subjected PAI-1-/- mice to treatment with fluoxetine, another SSRI largely used in clinic. Our data once again demonstrated the ineffectiveness of the antidepressant to reverse depressive symptoms of PAI-1-/- mice (see Additional file 5: Figure S4a: $U=68.5, P=0.611$; see Additional file 5: Figure S4b: $U=77.5, P=0.979$; see Additional file 5: Figure S4c: $U=53, P=0.303$; see Additional file 5: Figure S4d: $t=-1.28, P=0.214$; see 

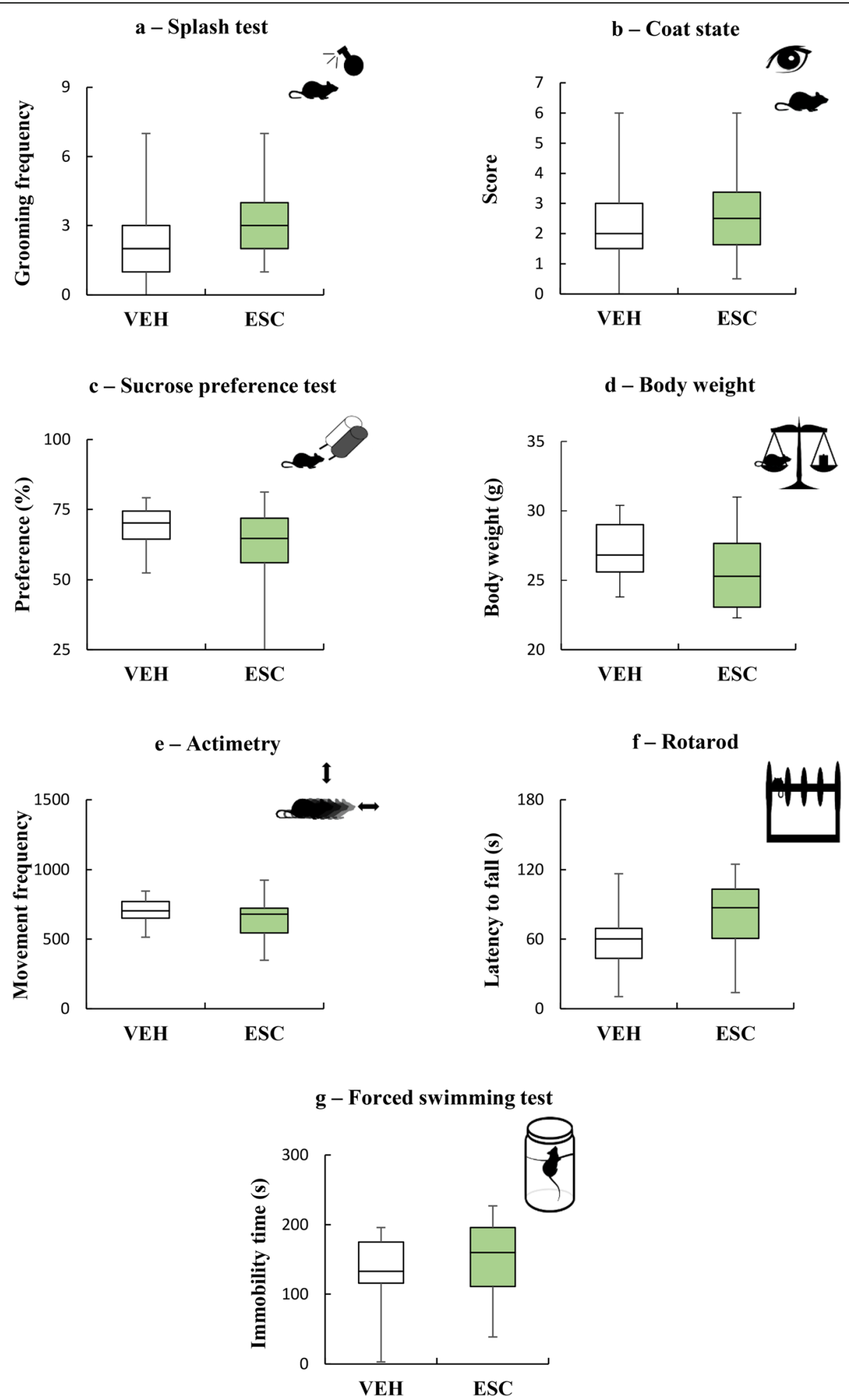

Fig. 4 PAl-1 knockout mice fail to respond to escitalopram treatment. Evaluation of the behavioral phenotype of PAl-1 knockout mice submitted to an escitalopram chronic treatment (35 days) at $15 \mathrm{mg} / \mathrm{kg}$. Escitalopram: ESC; Vehicle ( $\mathrm{NaCl} 0.9 \%)$ : VEH. $\mathbf{a}$ Splash test: $n_{\mathrm{VEH}}=17 ; \mathrm{n}_{\mathrm{ESC}}=18 . \mathbf{b}$ Coat state: $n_{V E H}=17 ; n_{E S C}=18 . \mathbf{c}$ Sucrose preference test: $n_{V E H}=17 ; n_{E S C}=18 . \mathbf{d}$ Body weight: $n_{V E H}=17 ; n_{E S C}=18$. e Actimetry: $n_{V E H}=17 ; n_{E S C}=17$. $\mathbf{f}$ Rotarod: $n_{V E H}=11 ; n_{E S C}=12 . \mathbf{g}$ Forced swimming test: $n_{V E H}=17 ; n_{E S C}=17$. Mann-Whitney U-tests $(\mathbf{a}, \mathbf{c}, \mathbf{d}, \mathbf{g})$, Student $t$ tests $(\mathbf{b}, \mathbf{e}, \mathbf{f}): P>0.05$. Boxplots show distributions with black horizontal lines indicating the median, box margins denoting the lower and upper quartiles. Whiskers show the minimum and maximum values 
Additional file 5: Figure S4e: $t=-1.16, P=0.259$; see Additional file 5: Figure S4f: $\mathrm{t}=1.86, P=0.078$; see Additional file 5: Figure S4 g: $U=47.5 ; P=0.160$ ).

\section{Discussion}

In the present study, we unveil an original genetic model of depression namely the deletion of PAI- 1 . By using a depression screening system adapted to mouse, we demonstrate that the deficiency of PAI-1 clearly results in a depressive-like phenotype. In accordance with the monoamine hypothesis of depression, we demonstrate that these phenotypic characteristics are associated with changes in monoamine levels in brain structures known to be involved in MDD. We then establish that the involvement of PAI-1 in depression is independent of the tPA-BDNF axis. Finally, because of the inefficacy of escitalopram and fluoxetine treatments, we authenticate the PAI-1-/- mice as a resistant-SSRI genetic model of depression.

The diagnosis of MDD in humans is established by the presence of at least five symptoms out of a list of nine, which must include depressed mood and / or anhedonia $[2,49]$. In our study, we chose to elaborate a depression screening system based on a large battery of behavioral tests since all data obtained can be combined to create a composite score which offers a more complete evaluation of the phenotype profile. The evaluation of PAI-1 -/ - mice showed the presence of six symptoms out of a list of seven in our behavioral screening system: anhedonia, apathy, weight loss, impairment in motivation/effort, self-centered behaviors deficit and cognitive dysfunction. Observed symptoms are multiple and in addition, they include mandatory primary criteria like in humans, providing an excellent face validity of the PAI-1 knockout mouse model.

To further explore the PAI-1-/- mouse model, we examined whether the depression-related behaviors of PAI-1-/- mice may be linked to monoamine transmission alterations. We observed a decrease of the concentrations of 5-HT and DA, two neurotransmitters identified for their involvement in MDD. Interestingly, this depletion in monoamine levels was found specifically in the prefrontal cortex, hippocampus, and dorsal raphe, three brain regions known to play a crucial role in psychic disorders $[10,21,25,28,33,39]$, including MDD. In this respect, the monoamines changes in PAI$1-/-$ mice demonstrate the construct validity of this animal model of depression. Electrochemical assays or microdialysis techniques would be relevant to measure the synaptic concentrations of neurotransmitters and thus to better understand the mechanisms underlying the role of PAI-1 in MDD.

We then examined the response of PAI-1-/- mice to antidepressant drugs. Chronic administration of escitalopram or fluoxetine did not reverse depressivelike behaviors. The inefficacy of treatments in PAI-1-/mice strongly suggests that the SSRIs mechanism of action is directly dependent of PAI-1. Our hypothesis is strengthened by Tsai et al.' study [48] demonstrating that the genetic variants of SERPINE1 gene in humans decrease the acute therapeutic response to SSRIs. Moreover, the present results confirm the assumption that antidepressants are less effective in conditions where vulnerability to depression, because of the presence of genetic, personality or developmental risks factor, is elevated $[51,52]$. Consequently, the PAI-1-/- mouse represents an excellent model of predisposition to depression for the characterization of future drug candidates for patients not responsive to current treatments.

Several authors have suggested that PAI-1 could be involved in the pathogenesis of MDD through inhibition of the cleavage of the proBDNF into mBDNF via its blockage of the proteolytic activity of tPA. Here, we demonstrate that the depressive-like phenotype induced by deficiency of PAI-1 is not dependent on the tPABDNF axis. First, tPA knockout mice do not exhibit depressive-like behaviors. Second, no variation of active tPA or mBDNF levels was observed in PAI-1-depressed mice relative to controls. It is possible to hypothesize that PAI-1 would act independently of tPA, as previously demonstrated for its ability to promote cell survival and neuronal network [42]. This question should be examined in more details in futures studies. Interestingly, tPA-deficient mice have been described to display behavioral disinhibition associated with a decrease of serotonin levels specifically in thalamus and caudate putamen [38]. These data are in direct line with ours, unequivocally demonstrating that cerebral selective impairments of the serotonin circuitry, mediated by tPA or PAI-1, predispose to specific and independent forms of emotional impairment.

Many clinical studies have shown elevated plasma PAI-1 levels in depressed patients $[14,22,24]$. In addition, a number of SERPINE1 genetic variants have been associated with MDD [48]. At the preclinical scale, increased cerebral and vascular PAI-1 concentrations have been found in rodents subjected to a CUMS procedure $[20,45]$. Corticosterone also markedly raises the levels of blood PAI-1 in mice [44]. One can postulate that PAI-1 could be involved in the negative feedback loop of the hypothalamic-pituitary-adrenal axis. In the absence of PAI-1 (PAI-1 knockout mice), the negative feedback does not lead to an elevated and unregulated cortisolemia, likely cause of depression pathogenesis. The role played by PAI-1 in MDD should be addressed with more details in future studies thanks to the development of new tools such as the generation of conditional PAI-1 knock-out mice. 


\section{Conclusions}

In summary, we provide here a new genetic model of depression, the PAI-1 knockout mouse, with strong face and construct validity. This preclinical model being in direct line with genetic variants of SERPINE1 gene observed in humans strengthens the fact that PAI-1 is a factor of predisposition to MDD. In addition, the PAI-1 knockout mouse is also a model of resistance to antidepressants such as SSRIs. Finally, this study provides the first demonstration of the involvement of PAI-1 in depression by a mechanism independent of BDNF, and suggests that PAI-1 could be an innovative target for the development of new drugs for MDD. Further investigations will be required to understand how the signaling cascades downstream of PAI-1 affect the risk of vulnerability to depression and engage the mental disorder.

\section{Supplementary information}

Supplementary information accompanies this paper at https://doi.org/10. 1186/s40478-019-0807-2.

\section{Additional file 1. Additional Materials and Methods. Animals.} Assessment of depressive-like behaviors (Splash test; Sucrose preference test; Body weight; Actimetry; Rotarod; Coat state; T-maze; Forced swimming test). Perfusion and sampling. Ultra-high-pressure liquid chromatography coupled with tandem-mass spectrometry (Analytical Methods; Quantification). Magnetic Resonance Imaging

Additional file 2: Figure S1. The depressive-like phenotype of PAI-1 $-/-$ mice is not attributed to any brain weight or volume disparity. Quantitative analyses of brain volume (a) and weight (b) in PAl-1 knockout mice (PAI-1 -/-) and of their wild-type littermates (PAI-1 +/+). (c) Representative T2-weighted images of PAl- $1-/-$ and PAl- $1+/+$ mice's brain. $n=3$ for each group. Mann-Whitney $U$-tests: $P>0.05$. Boxplots show distributions with black horizontal lines indicating the median, box margins denoting the lower and upper quartiles. Whiskers show the minimum and maximum values.

Additional file 3: Figure S2. tPA deficiency does not induce a depressive-like phenotype. Evaluation of the behavioral phenotype of tPA knockout mice (tPA-/-) and of their wild-type littermates (tPA+/+). (a) Splash test: $n_{\mathrm{tPA} /+}=20 ; n_{\mathrm{tPA}-/-}=20$. (b) Coat state: $n_{\mathrm{tPA}+/+}=20 ; n_{\mathrm{tPA}-/-}=$ 20. (c) Sucrose preference test: $n_{\mathrm{tPA} /+\mathrm{EE}}=20 ; n_{\mathrm{tPA}-/-\mathrm{EE}}=20$. (d) Body weight: $n_{\mathrm{tPA}+/ \mathrm{EE}}=15 ; n_{\mathrm{tPA}-/-}=15$. (e) Actimetry: $n_{\mathrm{tPA}+/+}=19 ; n_{\mathrm{tPA}-/-}=$ 20. (f) Rotarod: $n_{\mathrm{tPA}+/+}=20 ; n_{\mathrm{tPA}-/-}=20$. (g-h) T-maze: $n_{\mathrm{tPA}+/+}=15 ; n_{\mathrm{tPA}}$ ${ }_{-/-}=13$. Mann-Whitney U-tests (a-b), Student t tests (c-f), Wilcoxon signed-rank tests ( $g$-h): ${ }^{*} P<0.05$. Boxplots show distributions with black horizontal lines indicating the median, box margins denoting the lower and upper quartiles. Whiskers show the minimum and maximum values.

Additional file 4: Figure S3. PAI-1 knockout mice fail to respond to escitalopram treatment. Evaluation of the behavioral phenotype of PAI-1 knockout mice (PAl-1-/-) submitted to an escitalopram chronic treatment (35 days) at $30 \mathrm{mg} / \mathrm{kg}$. Escitalopram: ESC; Vehicle ( $\mathrm{NaCl} 0.9 \%): \mathrm{VEH}$. (a) Splash test: $n_{V E H}=12 ; n_{E S C}=12$. (b) Coat state: $n_{V E H}=12 ; n_{E S C}=12$. (c) Sucrose preference test: $n_{V E H}=12 ; n_{E S C}=12$. (d) Body weight: $n_{V E H}=12$; $n_{E S C}=12$. (e) Actimetry: $n_{V E H}=12 ; n_{E S C}=12$. (f) Rotarod: $n_{V E H}=12 ; n_{E S C}=$ 12. (g) Forced swimming test: $n_{V E H}=12 ; n_{E S C}=11$. Mann-Whitney U-tests $(a, c, e)$, Student t tests $(b, d, f, g): P>0.05$. Boxplots show distributions with black horizontal lines indicating the median, box margins denoting the lower and upper quartiles. Whiskers show the minimum and maximum values.

Additional file 5: Figure S4. PAI-1 knockout mice fail to respond to fluoxetine treatment. Evaluation of the behavioral phenotype of PAl-1 knockout mice (PAl-1-/-) submitted to a fluoxetine chronic treatment (35 days) at $15 \mathrm{mg} / \mathrm{kg}$. Fluoxetine: FLX; Vehicle ( $\mathrm{NaCl} 0.9 \%$ ): VEH. (a) Splash test: $n_{V E H}=12 ; n_{F L X}=13$. (b) Coat state: $n_{V E H}=12 ; n_{F L X}=13$. (c) Sucrose preference test: $n_{V E H}=11 ; n_{F L X}=13$. (d) Body weight: $n_{V E H}=12 ; n_{F L X}=13$. (e) Actimetry: $n_{V E H}=12 ; n_{F L X}=13$. (f) Rotarod: $n_{V E H}=10 ; n_{F L X}=11$. (g) Forced swimming test: $n_{V E H}=12 ; n_{F L X}=12$. Mann-Whitney U-tests (a-c, g), Student $t$ tests $(d-f): P>0.05$. Boxplots show distributions with black horizontal lines indicating the median, box margins denoting the lower and upper quartiles. Whiskers show the minimum and maximum values.

Additional file 6: Table S1. Number of mice used in the study.

Additional file 7: Table S2. Quantification modeling of depressive-like behaviors in mouse.

Additional file 8: Table S3. Multiple Reaction Monitoring (MRM) method parameters. The MRM product ions in brackets are uses as confirmation transitions.

\section{Abbreviations}

5-HMT: 5-hydroxy-N- $\omega$-methyltryptamine; 5-HT: Serotonin; BDNF: Brainderived neurotrophic factor; CUMS: Chronic unpredictable mild stress; DA: Dopamine; DHBA: 3,4-dihydroxybenzylamine; ESC: Escitalopram; FLX: Fluoxetine; FST: Forced swimming test; MDD: Major depressive disorder; MDE: Major depressive episodes; MRM: Multiple reaction monitoring; NA: Noradrenaline; PAI-1: Plasminogen activator inhibitor-1; SSRIs: Selective serotonin reuptake inhibitors; tPA: Tissue-type plasminogen activator; UHPLCMS/MS: Ultra-high-pressure liquid chromatography coupled with tandemmass spectrometry; VEH: Vehicle

\section{Authors' contributions}

DV and VA conceived and designed the study. HP, CD, MH, SL, SMDL, RD, $C F$, and MCB performed the experiments and analyzed the data. $H P, C D, M H$, $\mathrm{SL}, \mathrm{SMDL}, \mathrm{RD}, \mathrm{CF}, \mathrm{MCB}, \mathrm{PO}, \mathrm{OG}, \mathrm{ES}, \mathrm{LL}, J \mathrm{C}, \mathrm{DV}$ and VA interpreted the data. DV and VA drafted the manuscript. All authors revised the manuscript critically for important intellectual content. All authors approved the final version of the manuscript submitted.

\section{Funding}

This work was supported by grants from the INSERM (French National Institute for Health and Medical Research), the French Ministry of Higher Education, Research and Innovation, the Foundation for Medical Research (FRM/NDEQ20140329555) and the Regional Council of Lower Normandy. This project is also part of the following European research programs: 1/ European Marie Curie International Training Network "Neurolnflammation, FP7; 2/ NeuroAtlantic, An Atlantic innovation platform on diagnosis and treatment of neurological diseases and aging, EAPA 791/2018NEUROATLANTIC; 3/ H2020, International Marie Curie Training Network, ENTRAIN, Neuroinflammation, H2020-MSCA-ITN-2018 number 813294.

\section{Availability of data and materials}

The datasets used and/or analyzed during the current study are available from the corresponding author on reasonable request.

\section{Ethics approval}

All applicable international, national, and/or institutional guidelines for the care and use of animals were followed. All procedures involving animals were in accordance with the ethical standards set by the French ministry of education and research (agreement numbers APAFIS\#5115 and APAFIS\#4359). The principal investigator (VA, personal license number 14-73) was accredited by the "Direction Départementale des Services Vétérinaires". The animal investigations were performed under the current European directive (2010/63/EU) as incorporated in national legislation (Decree 87/848) and in authorized laboratories (GIP Cyceron; approval n E14118001). This article does not contain any study with human participants performed by any of the authors.

\section{Consent for publication}

Not applicable.

\section{Competing interests}

The authors declare that they have no competing interests. 


\section{Author details}

'UNICAEN, INSERM, INSERM UMR-S 1237, Physiopathology and Imaging of Neurological Disorders, Normandie University, 14000 Caen, France. ${ }^{2}$ University of Trento, Center for Mind/Brain Science, 38068 Rovereto, Italy. ${ }^{3}$ UNICAEN, PRISMM core facility, SF4206 ICORE, Comprehensive Cancer Center F. Baclesse, Normandie University, 14000 Caen, France. ${ }^{4}$ UNICAEN, Centre Universitaire de Ressources Biologiques (CURB), Normandie University, 14000 Caen, France. ${ }^{5}$ INSERM UMR-S U1148, Laboratory for Vascular and Translational Science, Paris Diderot University, Sorbonne Paris Cité University, 75013 Paris, France. ${ }^{6}$ Department of Neurology and Laboratory of Functional Neurosciences, EA 4559, Amiens University Hospital, 80054 Amiens, France. ${ }^{7}$ CNRS, LNC, Laboratory of Cognitive Neuroscience UMR 7291, Aix Marseille University, 13331 Marseille, France. ${ }^{8}$ UNICAEN, EA 7466, Imagery and Therapeutic Strategy in Schizophrenia, Normandie University, 14000 Caen, France. ${ }^{9}$ University Hospital, Adult Psychiatric Unit, Mobile Intensive Care Unit, 14000 Caen, France. ${ }^{10}$ Institut de Pharmacologie Moléculaire et Cellulaire, UMR 7275 CNRS-Université Côte d'Azur, Sophia Antipolis, 06560 Valbonne, France. ${ }^{11}$ Caen Normandie Hospital, Department for Clinical Research, 14000 Caen, France.

Received: 23 July 2019 Accepted: 8 September 2019

\section{Published online: 14 October 2019}

\section{References}

1. Al-harbi KS (2012) Treatment-resistant depression: therapeutic trends, challenges, and future directions. Patient Prefer Adherence 6:369-388. https://doi.org/10.2147/PPA.S29716

2. American Psychiatric Association (2013) Diagnostic and statistical manual of mental disorders, 5th edn. American Psychiatric Publishing, Arlington

3. Autry AE, Monteggia LM (2012) Brain-derived neurotrophic factor and neuropsychiatric disorders. Pharmacol Rev 64:238-258. https://doi.org/10. 1124/pr.111.005108

4. Björkholm C, Monteggia LM (2016) BDNF - a key transducer of antidepressant effects. Neuropharmacology 102:72-79. https://doi.org/10. 1016/j.neuropharm.2015.10.034

5. Burstein O, Franko M, Gale E, Handelsman A, Barak S, Motsan S, Shamir A, Toledano R, Simhon O, Hirshler Y, Chen G, Doron R (2017) Escitalopram and NHT normalized stress-induced anhedonia and molecular neuroadaptations in a mouse model of depression. PLoS One 12:e0188043. https://doi.org/10. 1371/journal.pone.0188043

6. Carmeliet P, Kieckens L, Schoonjans L, Cole M, Bronson R, Collen D, Mulligan RC (1993) Plasminogen activator Inhibitor-1 gene-deficient mice. J Clin Invest 92:2746-2755. https://doi.org/10.1172/JCl116892

7. Carmeliet $\mathrm{P}$, Schoonjans L, Kieckens L, Ream B, Degen J, Bronson R, De Vos R, van den Oord JJ, Collen D, Mulligan RC (1994) Physiological consequences of loss of plasminogen activator gene function in mice. Nature 368:419-424. https://doi.org/10.1038/368419a0

8. Caspi A, Sugden K, Moffitt TE, Taylor A, Craig IW, Harrington H, MCClay J, Mill J, Martin J, Braithwaite A, Poulton R (2003) Influence of life stress on depression: moderation by a polymorphism in the $5-\mathrm{HTT}$ gene. Science 301 : 386-389. https://doi.org/10.1126/science.1083968

9. Castrén E, Rantamäki T (2010) The role of BDNF and its receptors in depression and antidepressant drug action: reactivation of developmental plasticity. Dev Neurobiol 70:289-297. https://doi.org/10.1002/dneu.20758

10. Chang CH, Chen MC, Qiu MH, Lu J (2014) Ventromedial prefrontal cortex regulates depressive-like behavior and rapid eye movement sleep in the rat. Neuropharmacology 86:125-132. https://doi.org/10.1016/j.neuropharm.2014.07.005

11. Doron R, Lotan D, Versano Z, Benatav L, Franko M, Armoza S, Kately N, Rehavi M (2014) Escitalopram or novel herbal mixture treatments during or following exposure to stress reduce anxiety-like behavior through corticosterone and BDNF modifications. PLoS One 9:e91455. https://doi.org/ 10.1371/journal.pone.0091455

12. Dulawa SC, Holick KA, Gundersen B, Hen R (2004) Effects of chronic fluoxetine in animal models of anxiety and depression. Neuropsychopharmacology 29:1321-1330. https://doi.org/10.1038/sj.npp. 1300433

13. El-Hage W, Leman S, Camus V, Belzung C (2013) Mechanisms of antidepressant resistance. Front Pharmacol 4:146. https://doi.org/10.3389/ fphar.2013.00146

14. Eskandari F, Mistry S, Martinez PE, Torvik S, Kotila C, Sebring N, Drinkard BE, Levy C, Reynolds JC, Csako G, Gold PW, Horne M, Cizza G (2005) Younger, premenopausal women with major depressive disorder have more abdominal fat and increased serum levels of prothrombotic factors: implications for greater cardiovascular risk. Metabolism 54:918-924. https:// doi.org/10.1016/j.metabol.2005.02.006

15. Guintivano J, Kaminsky ZA (2016) Role of epigenetic factors in the development of mental illness throughout life. Neurosci Res 102:56-66. https://doi.org/10.1016/j.neures.2014.08.003

16. Hamon M, Blier P (2013) Monoamine neurocircuitry in depression and strategies for new treatments. Prog Neuro-Psychopharmacol Biol Psychiatry 45:54-63. https://doi.org/10.1016/j.pnpbp.2013.04.009

17. Holmes A, Rodgers RJ (2003) Prior exposure to the elevated plus-maze sensitizes mice to the acute behavioral effects of fluoxetine and phenelzine. Eur J Pharmacol 459:221-230. https://doi.org/10.1016/S0014-2999(02)02874-1

18. Idell RD, Florova G, Komissarov AA, Shetty S, Girard RBS, Idell S (2017) The fibrinolytic system: a new target for treatment of depression with psychedelics. Med Hypotheses 100:46-53. https://doi.org/10.1016/j.mehy.2017.01.013

19. IsHak WW, Mirocha J, James D, Tobia G, Vilhauer J, Fakhry H, Pi S, Hanson E, Nashawati R, Peselow ED, Cohen RM (2015) Quality of life in major depressive disorder before/after multiple steps of treatment and one-year follow-up. Acta Psychiatr Scand 131:51-60. https://doi.org/10.1111/acps.12301

20. Isingrini E, Belzung C, d'Audiffret A, Camus V (2011) Early and late-onset effect of chronic stress on vascular function in mice: a possible model of the impact of depression on vascular disease in aging. Am J Geriatr Psychiatry 19:335-346. https://doi.org/10.1097/JGP.0b013e318202bc42

21. Jasinska AJ, Lowry CA, Burmeister M (2012) Serotonin transporter gene, stress and raphe-raphe interactions: a molecular mechanism of depression. Trends Neurosci 35:395-402. https://doi.org/10.1016/j.tins.2012.01.001

22. Jiang H, Li X, Chen S, Lu N, Yue Y, Liang J, Zhang Z, Yuan Y (2016) Plasminogen activator Inhibitor-1 in depression: results from animal and clinical studies. Sci Rep 6:30464. https://doi.org/10.1038/srep30464

23. Khawam EA, Laurencic G, Malone DA (2006) Side effects of antidepressants: an overview. Cleve Clin J Med 73:351-353 356-361

24. Lahlou-Laforet $K$, Alhenc-Gelas M, Pornin M, Bydlowski S, Seigneur E, Benetos A, Kierzin J-M, Scarabin P-Y, Ducimetiere P, Aiach M, Guize L, Consoli SM (2006) Relation of depressive mood to plasminogen activator inhibitor, tissue plasminogen activator, and fibrinogen levels in patients with versus without coronary heart disease. Am J Cardiol 97:1287-1291. https://doi.org/10.1016/j.amjcard.2005.11.062

25. Lebow MA, Chen A (2016) Overshadowed by the amygdala: the bed nucleus of the stria terminalis emerges as key to psychiatric disorders. Mol Psychiatry 21:450-463. https://doi.org/10.1038/mp.2016.1

26. Lee R, Kermani P, Teng KK, Hempstead BL (2001) Regulation of cell survival by secreted Proneurotrophins. Science 294:1945-1948. https://doi.org/10. 1126/science.1065057

27. Lopizzo N, Bocchio Chiavetto L, Cattane N, Plazzotta G, Tarazi Fl, Pariante CM, Riva MA, Cattaneo A (2015) Gene-environment interaction in major depression: focus on experience-dependent biological systems. Front Psychiatry 6:68. https://doi.org/10.3389/fpsyt.2015.00068

28. Lorenzetti $\bigvee$, Allen NB, Fornito A, Yücel M (2009) Structural brain abnormalities in major depressive disorder: a selective review of recent MRI studies. J Affect Disord 117:1-17. https://doi.org/10.1016/j.jad.2008.11.021

29. Lu B, Pang PT, Woo NH (2005) The yin and yang of neurotrophin action. Nat Rev Neurosci 6:603-614. https://doi.org/10.1038/nrn1726

30. Mao L, Kawao N, Tamura Y, Okumoto K, Okada K, Yano M, Matsuo O, Kaji H (2014) Plasminogen activator Inhibitor-1 is involved in impaired bone repair associated with diabetes in female mice. PLoS One 9:e92686. https://doi. org/10.1371/journal.pone.0092686

31. Masand PS, Gupta S (2002) Long-term side effects of newer-generation antidepressants: SSRIS, venlafaxine, nefazodone, bupropion, and mirtazapine. Ann Clin Psychiatry Off J Am Acad Clin Psychiatr 14:175-182. https://doi. org/10.1023/A:1021141404535

32. Matthews KA, Schott LL, Bromberger J, Cyranowski J, Everson-Rose SA, Sowers MF (2007) Associations between depressive symptoms and inflammatory/ hemostatic markers in women during the menopausal transition. Psychosom Med 69:124-130. https://doi.org/10.1097/01.psy.0000256574.30389.1b

33. Moustafa AA (2013) Increased hippocampal volume and gene expression following cognitive behavioral therapy in PTSD. Front Hum Neurosci 7:747. https://doi.org/10.3389/fnhum.2013.00747

34. Otte C, Gold SM, Penninx BW, Pariante CM, Etkin A, Fava M, Mohr DC, Schatzberg AF (2016) Major depressive disorder. Nat Rev Dis Primer 2:16065. https://doi.org/10.1038/nrdp.2016.65 
35. Pang PT, Teng HK, Zaltsev E, Woo NT, Sakata K, Zhen S, Teng KK, Yung W, Hempstead BL, Lu B (2004) Cleavage of proBDNF by tPA/plasmin is essential for long-term hippocampal plasticity. Science 306:487-491. https://doi.org/ 10.1126/science. 1100135

36. Pawlak R, Magarinos AM, Melchor J, McEwen B, Strickland S (2003) Tissue plasminogen activator in the amygdala is critical for stressinduced anxiety-like behavior. Nat Neurosci 6:168-174. https://doi.org/ 10.1038/nn998

37. Polyakova M, Stuke K, Schuemberg K, Mueller K, Schoenknecht P, Schroeter ML (2015) BDNF as a biomarker for successful treatment of mood disorders: a systematic \& quantitative meta-analysis. J Affect Disord 174:432-440. https://doi.org/10.1016/j.jad.2014.11.044

38. Pothakos K, Robinson JK, Gravanis I, Marsteller DA, Dewey SL, Tsirka SE (2010) Decreased serotonin levels associated with behavioral disinhibition in tissue plasminogen activator deficient (tPA-/-) mice. Brain Res 1326:135142. https://doi.org/10.1016/j.brainres.2009.12.095

39. Price JL, Drevets WC (2012) Neural circuits underlying the pathophysiology of mood disorders. Trends Cogn Sci 16:61-71. https://doi.org/10.1016/j.tics. 2011.12.011

40. Rapaport MH, Clary C, Fayyad R, Endicott J (2005) Quality-of-life impairment in depressive and anxiety disorders. Am J Psychiatry 162:1171-1178. https:// doi.org/10.1176/appi.ajp.162.6.1171

41. Saltiel P, Silvershein D (2015) Major depressive disorder: mechanism-based prescribing for personalized medicine. Neuropsychiatr Dis Treat 11:875-888. https://doi.org/10.2147/NDT.S73261

42. Soeda S, Koyanagi S, Kuramoto Y, Kimura M, Oda M, Kozako T, Hayashida S, Shimeno H (2008) Anti-apoptotic roles of plasminogen activator inhibitor-1 as a neurotrophic factor in the central nervous system. Thromb Haemost 100:1014-1020. https://doi.org/10.1160/TH08-04-0259

43. Sorregotti T, Mendes-Gomes J, Rico JL, Rodgers RJ, Nunes-de-Souza RL (2013) Ethopharmacological analysis of the open elevated plusmaze in mice. Behav Brain Res 246:76-85. https://doi.org/10.1016/j. bbr.2013.02.035

44. Tamura Y, Kawao N, Yano M, Okada K, Okumoto K, Chiba Y, Matsuo O, Kaji H (2015) Role of plasminogen activator Inhibitor-1 in glucocorticoidinduced diabetes and osteopenia in mice. Diabetes 64:2194-2206. https:// doi.org/10.2337/db14-1192

45. Tang M, Jiang P, Li H, Cai H, Liu Y, Gong H, Zhang L (2015) Antidepressantlike effect of n-3 PUFAs in CUMS rats: role of tPA/PAl-1 system. Physio Behav 139:210-215. https://doi.org/10.1016/j.physbeh.2014.11.054

46. Teng HK, Teng KK, Lee R, Wright S, Tevar S, Almeida RD, Kermani P, Torkin R, Chen Z-Y, Lee FS, Kraemer RT, Nykjaer A, Hempstead BL (2005) ProBDNF induces neuronal apoptosis via activation of a receptor complex of p75NTR and Sortilin. J Neurosci 25:5455-5463. https://doi.org/10.1523/JNEUROSCI. 5123-04.2005

47. Tsai S-J (2017) Role of tissue-type plasminogen activator and plasminogen activator inhibitor-1 in psychological stress and depression. Oncotarget 8 : 113258-113268. https://doi.org/10.18632/oncotarget.19935

48. Tsai S-J, Hong C-J, Liou Y-J, YW-Y Y, Chen T-J (2008) Plasminogen activator inhibitor-1 gene is associated with major depression and antidepressant treatment response. Pharmacogenet Genomics 18:869-875. https://doi.org/ 10.1097/FPC.0b013e328308bbc0

49. Uher R, Payne JL, Pavlova B, Perlis RH (2014) Major depressive disorder in DSM-5: implications for clinical practice and research of changes from DSMIV. Depress Anxiety 31:459-471. https://doi.org/10.1002/da.22217

50. Vos T, Abajobir AA, Abate KH, Abbafati C, Abbas KM, Abd-Allah F et al (2017) Global, regional, and national incidence, prevalence, and years lived with disability for 328 diseases and injuries for 195 countries, 1990-2016: a systematic analysis for the Global Burden of Disease Study 2016. Lancet 390: 1211-1259. https://doi.org/10.1016/S0140-6736(17)32154-2

51. Willner P, Belzung C (2015) Treatment-resistant depression: are animal models of depression fit for purpose? Psychopharmacology 232:3473-3495. https://doi.org/10.1007/s00213-015-4034-7

52. Willner P, Scheel-Krüger J, Belzung C (2014) Resistance to antidepressant drugs: the case for a more predisposition-based and less hippocampocentric research paradigm. Behav Pharmacol 25:352-371. https://doi.org/10.1097/FBP.0000000000000066

53. Woo NH, Teng HK, Siao C-J, Chiaruttini C, Pang PT, Milner TA, Hempstead BL, Lu B (2005) Activation of p75NTR by proBDNF facilitates hippocampal long-term depression. Nat Neurosci 8:1069-1077. https:// doi.org/10.1038/nn1510
54. Zhou C, Zhong J, Zou B, Fang L, Chen J, Deng X, Zhang L, Zhao X, Qu Z, Lei Y, Lei T (2017) Meta-analyses of comparative efficacy of antidepressant medications on peripheral BDNF concentration in patients with depression. PLoS One 12:e0172270. https://doi.org/10.1371/journal.pone.0172270

\section{Publisher's Note}

Springer Nature remains neutral with regard to jurisdictional claims in published maps and institutional affiliations.
Ready to submit your research? Choose BMC and benefit from:

- fast, convenient online submission

- thorough peer review by experienced researchers in your field

- rapid publication on acceptance

- support for research data, including large and complex data types

- gold Open Access which fosters wider collaboration and increased citations

- maximum visibility for your research: over $100 \mathrm{M}$ website views per year

At $\mathrm{BMC}$, research is always in progress.

Learn more biomedcentral.com/submissions 